\title{
SOIL FORMATION IN SWAMP SOILS OF THE COASTAL FRINGE OF SURINAM
}

\author{
P.G.E.F. ALUGUSTINUS and S. SLAGER \\ Laboratory for Physical Geography, State University, Utrecht (The Netherlands) \\ Laboratory for Regional Soil Science, State Agricultural University, Wageningen (The Netherlands)
}

(Received December 16, 1970)

\begin{abstract}
Augustinus, P.G.E.F. and Slager, S., 1971. Soil formation in swamp soils of the coastal fringe of

Surinam. Geoderma, 6: 203-211.

This paper presents data on the sedimentation processes along the Surinam coast, the resulting deposits and soil formation in the young Holocene marine clay soils.

Along the Surinam coast two types of materials were observed: fine-textured (clay) and coarsetextured materials (sand and shells). They originate from different sources, are transported along different ways and are deposited separately.

Three types of coasts were distinguished: an erosional, a sand accretionary and a mud accretionary coast. Behind the erosional coast and the sand accretionary one salt pans may develop with a sparse vegetation and impervious stiff clays. Behind a mud accretionary coast a brackish water swamp generally developes, which may be nearly always inundated or periodically dry. In the wet swaincs an accumulation of pyrite occurs, but little or no oxidative soil formation. In the periodically dry swamps the accumulation of the pyrite is alternated by oxidative soil formation and compaction.

Ultimately four groups of soils were recognized which differ from each other in acidity and permeability and consequently have different agricultural potentialities.
\end{abstract}

\section{INTRODUCTION}

The major part of Surinam consists of a strongly dissected hilly landscape (Interior Uplands) with deeply weathered Precambrian rocks. To the north it is bordered by the so-called Coverlandscape (Van der Eyk, 1957), which is slightly undulating, and built up with terrestrial sediments, originating from weathering and subsequent erosion of the Precambrian rocks of the Interior Uplands. To the north of this Coverlandscape there is a rather flat coastal plain, which may be divided into an old (Pleistocene) and a young (Holocene) coastal plain.

The young coastal plain consists of an alternation of marine clayey and sandy deposits, locally dissected by wide rivers and their adjacent fluviatile and estuarine deposits. The soils developed in the marine clays especially were the subject of the research by the second author in his studies on soil survey, soil formation and soil suitability.

Although the soils under consideration appear the same at first sight (i.e., when using a soil auger), their differences become striking on a more detailed investigation. Their 
main differences are their physical properties, in particular their water permeability, which could be noticed from the soil profile by structure and bioporosity. The fact that these differences occur at very short distances make it even more complicated. They are not visible in the present landscape.

After a thorough investigation, it became obvious that the just-mentioned differences originate from varying conditions during and shortly after sedimentation of the deposits. The latter was one of the major subjects of the coast-morphological research of the first author.

This paper will provide data about sedimentation processes along the Surinam coast, the properties of the resulting deposits and the therein developed soils.

\section{OBSERVATIONS}

\section{Origin and sedimentation of parent materials}

Along the Surinam coast two types of materials were noticed, fine-textured materials (clays) and coarse-textured materials (sand and shells). They originate from different sources, are transported along different ways and are deposited separately.

It is generally accepted, although there is no conclusive evidence, that the clay originates from the Amazon Piver and is transported in suspension (e.g., IJzerman, 1931; Zonneveld, 1951, Reyne, 1961).

The Amazon discharges every year many millions of tons of fine materials in to the Atlantic Ocean. This material is transported along the north coast of South America by the South Equatorial Current and by an inshore, so-called Residual Current (Diephuis, 1966).

Referring to other workers in this field it may be stated that sand originates either from parts of the coast of French Guiana and from some of the Surinam rivers (Krook, 1966) or from some of the Surinam rivers only (IJzerman, 1931; Zonneveld, 1954). It was found that sand is transported by turbulence in the surf zone in a westerly direction by means of beachdrift.

The shells found on the Surinam coast originate from shell animals living on the bottom of the sea within the zone of the coastal waters. After the death of the shell animals, the shells are transported to the coast.

The deposition of sediments on the Surinam coast is rather complicated, being an alternation of deposition of clay on the one hand and sand and/or shells on the other.

The clay is concentrated in mud flats connected to the existing coast. The mud flats consist of sling mud. Sling mud, according to Diephuis (1966), is a gel, which forms if a concentration of fine particles higher than a critical value is reached. The particles form a structure that settles as a whole. The sling mud gradually changes into an unripe clay by settling of the particles. At the same time new sediments are supplied, thus gradually piling up the deposits. In the sling mud small fishes (Gobionellus oceanicus (Pallas)) may be present (and generally are) in large numbers. They were found in sling muds which fell dry for only short periods per day. During these periods they fled into holes which they make in the sling mud. If they are present they disturb the sedimentary stratification. As the mud flat increases in height, it falls dry for longer periods per day. As soon as the 
surface of the mud flat becomes higher than the mean tide level. Parwa ( $A$ vicennia nitida) may start to grow on it. Avicennia nitida is a mangrove vegetation with a shallow network of roots.

On these roots grow pneumatophores which end above the soil surface, and which provide the roots with oxygen. These pneumatophores form a field of pins, with diameters up to about one centimeter, standing around the tree. When the pneumatophores die they leave a more or less extended network of open vertical tubes. As the soil surface is raised by supply of new sediments the pneumatophores become longer so as to remain with their ends above the soil surface. Moreover, new rootsystems and new pneumatophores may be formed. The density of the Avicennia forest may vary and the number of pneumatophores per tree may vary also. Consequently the numbers of vertical tubes left after dying of the magrove vegetation may vary. The diameter of the pneumatophores was found to be rather constant between 5 and $12 \mathrm{~mm}$.

As soon as, or somewhat earlier than the Avicennia starts to grow on a sediment, crabs will also start to inhabit that sediment. They largely dig through the sediment and mix its components, giving oxygen the possibility to start oxidizing the sediment, leaving an unstratified deposit.

In summary it may be said that, when an $A$ vicennia forest dies, a deposit is left behind which is more or less porous and generally not stratified. Along the coast of Surinam an alternation is found of coastal sections with a mud flat and sections without. The type of coastal formation described above will be called a mud accretionary coast.

Theoretically there should at present be marine erosion, by means of surf action along the entire coast of Surinam. Those sections, however, which have mudflats are for the most part protected against erosion, since the sling mud of the mud flat subdues the wave action. As has been shown in Fig. 1, the eastern side of the mud flat is eroded more or less and the resulting material is deposited at the western side as sling mud. In some cases the mud flat with the Avicennia on it is entirely removed; sometimes, however, a strip of the mud flat with the Avicennia is left behind, resulting in a net clay accretion in comparison to the situation before arrival of the mud flat.

Those place which are no longer protected by the mud flat are attacked by marine erosion. If less sand and/or shells is supplied by the surf action than is eroded by the

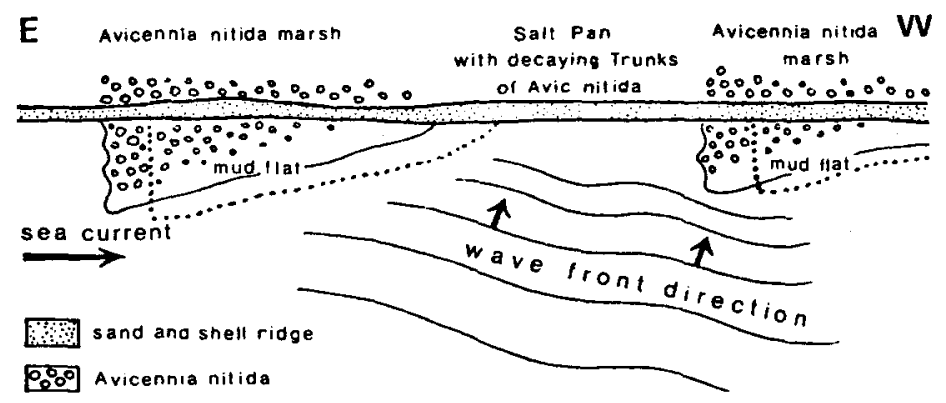

Fig. 1. Diagram showing the westward shifting alternation of erosional and sedimentary landscapes and indicating current and wave direction. The westward movement of the mudflats is indicated by the broken lines. 
surf action from the existing coast, an erosional coast results; if, however, more sand and, or shells is supplied by the surf action than is eroded by the surf action from the existing coast, a sand accretionary coast results. So both an erosional and a sand accretionary coast are bounded by a sand or a shell beach ridge, although of a different shape. Soil de. velopment on these ridges will not be discussed in this paper. In the formation of both types of coasts the Avicennia vegetation, which is possibly present, dies, i.e., in the casc of an erosional coast it is removed and in the case of a sand accretionary it dies in situ.

In both cases, behind the beach ridge a salt pan develops, which is rather stable in the case of a sand accretionary coast, but unstable in the case of an erosional coast. Basically it is a clay plain from which the Avicennia has died. This clay pan receives seawater at spring tide and occasionally at high tide, which cannot flow back to the sea. This water contains, apart from salts, some clay particles. The water is removed by evaporation thus giving rise to an increased salt content. This may amount up to several percents, causing the death of the Avicennia vegetation. In the dry season the following plant species may be found, viz., Batis maritima and to a lesser extent Sesuvium portulacastrum. The sedimentation of clay in the salt plains without vegetation or with a sparse vegetation, results in the formation of a fine-textured, well-ripened, impervious clay-cover with very few or no pyrites and a strongly physicogenic structure (Slager, 1966). It is not more than some decimeters thick and overlies sediments deposited under an $A$ vicennia vegetation. These clay plains have a distinctly elongated shape, parallel to the coast, the maximum width being not more than some hundreds of metres.

\section{Soil formation under brackish and sweet water swamp conditions}

In case of a mud accretionary coast, a brackish water swamp is formed at the landward side of the Avicennia zone. If the swamp area is not interrupted by ridges of sand or shells, a wide Avicennia zone may have formed. In the areas which have been investigated, the width of the brackish water swamp varied with the width of the Avicennia zone, i.e., if the Avicennia zone was wide, the brackish water swamp was also wide (cf., near Bigi Pan, where both areas have widths of several kilometers, while in the region north of Paramaribo both zones have widths of not more than some tens of metres). It is unknown if there is a causal relation between the widths of the two zones. The change from the Avicennia zone to the brackish water swamp is rather abrupt. The brackish composition of the water in these swamps results from a mixture of seawater and rainwater. Periodically it may, however, be much more saline than the seawater and in other periods much fresher (during the dry and the wet seasons respectively). Much variation is found in the hydrological regimes of these swamps, due to their topography and location. Nearly every year some of them dry out to a depth of about $1 \mathrm{~m}$, while in others nearly always some water remains before they are reclaimed. A whole range lies between these extremes. The main vegetation in these marshes is Eleocharus mutata.

Pyrite is accumulated in these swamps. This type of pyrite is called tertiary pyrite (Pons, 1965). It is found in a peat layer on the soil surface. In the marine deposits of the coastal plain of Surinam this tertiary pyrite occurs in a higher concentration than the primary pyrite (deposited together with the sediments) and the secondary pyrite (accumulated by the organic material originating from the Avicennia vegetation. The primary 
and secondary pyrites generally amount to up to 0.5 or $1 \%$ by weight, while the tertiary pyrite may amount up to some $6 \%$. The amount of the tertiary pyrite depends among other things on the length of the period during which the swamp is brackish..

In the brackish swamps which are mostly wet, little or no oxidative soil formation takes place. Little or none of the tertiary pyrite is oxidized under these wet conditions. Before reclamation it still consists of an immature sediment with more or less biopores, resulting from the pneumatophores of the Avicennia and covered with a peat layer which may be (and generally is) rich in pyrite.

In the brackish swamp, however, which periodically dries up, soil formation is active. During the dry seasons, when the soil dries up, fissures are formed, due to shrinkage of the heavy clays. Through the fissures and the biopores oxygen penetrates the soil and oxidizes part of the ferrocompounds. The ferri-hydroxides formed are found back as subcutanic features (Slager et al., 1970) mainly around biopores. They are called ironpipes in the field (Van Amson, 1966). The pyrites do not oxidize.

The most interesting process, from an agricultural point of view, and which takes place in the periodically drying out brackish swamps, is compaction. Two processes give rise to this compaction: ripening of the soil and illuviation of a groundmass from the surface soil. During the ripening the soil loses water irreversibly and n-values decrease. At the same time fissures are formed, leaving prismatic peds between them. On further desiccation the prismatic peds are subdivided by fragmentation into small angular blocky elements (Slager and Schuylenborgh, 1970). At the same time stress is induced into the subsoil, in which some fissures occur. One cause of this stress is due to the unequal water extraction by the roots. Another reason of stress is an uneven remoistening of the subsoil at the beginning of the wet season, or it is initiated by the movement of surface soil into the subsoil (either as peds or as suspension). This stress is compensated for by plastic flow, which is obvious from the presence of masepic plasmic fabrics in these subsoils (Slager et al., 1970). This plastic flow in turn causes resettlement of peds in the overlying layers. The whole process results in the formation of a surface soil, which is considerably denser than would be expected from a clay layer, rich in water, which dries up. The plastic flow disrupts part of the existing biopores in the subsoil. As the ripening proceeds the plastic flow stops and peds are formed in the subsoil also. On these peds stress cutans appear. As in Vertisols (Blokhuis et al, 1970), these stress cutans increase in abundance with increasing depth within the zone of seasonal drying. These cutans appear to develop when the soil material within the peds swells on remoistening against the pressure of the overlying soil layers. In the first place the stress cutans close the peds, thus disconnecting the biopores in two adjacent peds. In the second place the formation of stress cutans includes a certain degree of churning as can readily be demonstrated in the field: in the deepest layers vertical biopores are found, somewhat higher they begin to waddle and in the surface soil they gradually become entirely disrupted. At the same time the irontubes change into iron mottles or soft nodules (Slager et al., 1970). It should be stressed that this process of internal soil movement starts in the brackish swamp-water phase, but when it is in motion it proceeds when the swamp changes to a fresh water swamp and even after reclamation.

The second process which results in compaction is illuviation of the groundmass of the surface soil. When the soil material dries out in the dry season, the salt content in the surface soil increases considerably. When the first rainwater starts to flow through the 
fissures and biopores (as long as the latter are still present in the surface soil) at the beginning of the wet season, the electrolyte concentration in the soil solution in the vicinity of the pores decreases; peptization takes place and part of the soil mass flows to the sub. soil. This material is found back both in the field and in thin sections. In the latter it was observed as having the same texture as the material already present in the subsoil, but containing more fine organic particles and few or no oriented clay domains. This illuviation of groundmass was observed as coatings of biopores (channelmatrans, according to Brewer, 1964) or as complete fillings of biopores (iso-pedotubules) or as planar bodies filling former fissures. In the field the illuviated material was noticed to be distinctly grayer (probably more reduced due to a higher organic-matter content) than the surrounding soil matrix. It was found in the field mainly as fillings of biopores. It is obvious that this illuviation of the groundmass contributes to the churning process as the replacement of fine peds from the surface soil do in certain Vertisols. Unlike the compaction resulting from the ripening, the compaction due to illuviation of groundmass is restricted. to the periodically dyring out brackish swamps.

Both the periodically drying out and the nearly always wet brackish water swamps gradually become fresh-water swamps. The vegetation changes as to include one or more of the following plant species: Triplaris surinamensis, Euterpe oleraceae, Tabebuia spec., Pterocarpus officinalis, Cyperaceae and grasses. Under these conditions no pyrite is accumulated. In the fresh-water swamps which are nearly always wet, little or no soil formation takes place. In the periodically drying out fresh-water swamps soil formation proceeds, although in a somewhat different way than before. Ripening proceeds, including stress cutan formation, disruption of biopores and churning. Illuviation of groundmass from the surface soil stops. Ferro-compounds are oxidized to ferrihydroxides, which in the beginning occur as subcutanic features and on churning are transformed into ferric nodules. Pyrites are oxidized, especially the secondary and tertiary pyrites, since they occur in places where oxygen can readily penetrate.

Finally the swamps are reclaimed. Then in all of the above described soils soil formation starts or proceeds as in the periodically drying out fresh water swamps: oxidation of pyrites and ferro-compounds and ripening. Many other soil forming processes are active (cf., Slager and Van Schuylenborgh, 1970), but they will not be discussed here.

\section{DISCUSSION}

Up till now we have consequently discussed the soils in two groups: those in the wet swamps and those in the periodically dry swamps. In reality much more variation is present. Therefore we will summarize the different factors which may influence the discussed soils before they are reclaimed.

\section{Sedimentation phase}

Counts of the number pneumatophores of Avicennia trees revealed that a strong variation occurs in the abundance per square meter. In certain areas the number of pins per surface unit around all trees is lower than in other areas. Within the same area the number of pins per square meter per tree may be different. Finally between the spheres of 
Avicennia trees, areas remain which have no pneumatophores at all; the surface area of these blank spaces is a function of the density of the Avicennia forest.

\section{Brackish-water swamp phase}

We have discussed the compaction in these swamps due to ripening and due to peptization, followed by illuviation of groundmass from the surface soil and we have discussed the acccumulation of tertiary pyrite. The compaction due to ripening depends on the depth and intensity of desiccation, on the length of the period in which the desiccation occurs each year and finally on the number of years during which the alternate drying and rewetting take place. In general it is a function of the fluctuation of the groundwater and surface-water levels respectively. The water level in turn is determined physiographically either by the absolute height of the swamp or by the degree of enclosure by ridges. The compaction due to illuviation depends also on the fluctuation of the groundwater and the surface-water-level. Moreover, the salinity of the water is important. This salinity depends among other things on the accessibility of seawater to the swamp. The accumulation of tertiary pyrite depends on the total period of flooding with brackish water.

\section{Fresh-water swamp phase}

As discussed before, only the compaction due to ripening is important in this stage. It depends on the same factors as in the brackish water swamp.

Although from different combinations of the various factors mentioned above a large number of different soils could theoretically result, in practice only a restricted number of different soils are found after reclamation. The groups of soils which have been recognized up till now will be discussed.

\section{Extremely porous, rather acid soils}

Areas with soils of this type (cf., Slager and Van Schuylenborgh, 1970, profile Ma Retraite) have a mean water permeability of several meters per day. Detailed investigations revealed, however, that the water permeability may vary from meter to meter as do the number of large biopores. Stress cutans and illuviation of groundmass from the surface soil are absent. The biopores with their adjacent ferric subcutanic features run mainly in a vertical direction. Tertiary pyrite occurs in a superficial peat layer in which the content may amount up to several weight percents. The soil is acid, although not harmful for plant growth, throughout the oxidized zone. The $\mathrm{pH}$ increases extremely sharply when passing the oxidation-reduction boundary in the soil. Obviously this soil results from deposits, sedimented under a well-developed Avicennia forest. Later these deposits have never been dry for long periods till they were reclaimed. Pons (1965) called such soils "pseudo-catclays". 
Extremely impervious, slightly acid soils

These soils are characterized by peds (especially in the subsoil) which show distinct to prominent stress cutans. Within the peds a fairly high number of large biopores occur, although also types are known with few biopores. They may have illuviation of groundmass from the surface soil, but many of them are without. They all have relatively few tertiary pyrites in a superficial peat layer. The $\mathrm{pH}$ gradually increases with increasing depth and does not show a marked increase when passing the oxidation-reduction boundary. These soils apparently result from either a well-developed or a poorly developed Avicennia forest. The deposits later underwent a period of brackish water swamps, with periodical desiccation. Conditions during this phase and the length of this period may have varied strongly.

\section{Slightly acid, relatively porous soils}

These soils have a fairly high number of biopores, which run mainly in vertical direc. tion. Stress cutans are rare or occur in small amounts. Illuviation of groundmass from the surface soil may or may not be present, but generally it is not of much importance- Such soils have rather low contents of tertiary pyrites in a superficial peat layer. These soils have developed from sediments deposited in a normal Avicennia forest, and later on passed rather quickly through the brackish swamp phase.

Very impervious soils, with a very acid surface soil

These soils look very much like soils of the second group, with the exception of a surface soil with a low $\mathrm{pH}$ and a very low base saturation. Slager and Van Schuylenborgh (1970) described an example of such a soil as profile Santo. The content of tertiary pyrites is higher than in the soils of the second group. Unlike soils of the first group where on oxidation of the tertiary pyrite the soils material is acidified over a great depth (due to a high permeability), in soils of the fourth group the acids produced accumulate in the surface soil and give rise there to an extreme acidity. These soils probably originate from a renewed flooding with brackish water following on a phase of ripening in a periodically dry brackish water swamp.

Although these four groups of soils belong to the same subgroup (Hydric Tropaquepts, cf., Slager and Van Schuylenborgh, 1970) of the U.S. soil classification (U.S. Soil Survey Staff, 1960, 1967), they have divergent properties. Their agricultural potentialities consequently are different. In our opinion they should be classified into different families at a lower level of classification.

\section{ACKNOWLEDGEMENTS}

The first author wishes to express his gratitude to the Netherlands Foundation for the Advancement of Tropical Research, which enabled him to perform the studies, part of which have been presented here. He is further indebted to Dr. Boeseman, Royal Museum for Natural History, Leiden, for determination of the Gobionellus oceanicus (Pallas). The 
second author gratefully acknowledges Mr. G.E. Kamerling for cooperation in the investigations on pyrite and for many interesting discussions on the subject treated in this paper. $\mathrm{He}$ is further indebted to Prof. Pons for giving helpful suggestions for improving the manuscript.

\section{REFERENCES}

Blokhuis, W.A., Slager, S. and Van Schagen, R.H., 1970. Plasmic fabrics of two Sudan Vertisols. Geoderma, 4(2): 127-137.

Brewer, R., 1964. Fabric and Mineral Analysis of Soils. Wiley, New York, London, Sydney, $470 \mathrm{pp}$.

Diephuis, J.G.H.R., 1966. The Guiana Coast. Tïdschr. Koninkl. Ned. Aardrijkskundig Genoot. 83(2): $145-152$.

Krook, L. 1966. Investigations on the mineralogical composition of Tertiary and Quaternary sands in northern Surinam. Guiana Geol. Conf., 7th, Paramaribo, 1966, $21 \mathrm{pp.}$

Pons, L.J., 1965. Pyrites as a factor controlling chemical ripening and formation of "catclay" with special reference to the coastal plain Surinam. Bull. Agr. Expt. Sta. Paramaribo, 82: 141-161.

Reijne, A., 1961. On the contribution of the Amazon River to accretion of the coast of the Guianas. Geol. Mijnbouw, NS 23: 219-226.

Slager, S.,1966. Morphological Studies of some Cultivated Soils. Thesis, Wageningen, Agr. Res. Reports, Pudoc, 670, $22 \mathrm{pp}$.

Slager, S., Pons, L.J. and Jongmans, A.G., 1970. Micromorphology of some tropical alluvial clay soils. J. Soil Sci., 21(2): 233-241.

Slager, S. and Van Schuylenborgh, J., 1970. Morphology and geochemistry of three clay soils in a tropical coastal plain (Surinam). Agr. Res. Reports, Pudoc, 734: 24 pp.

Soil Survey Staff, 1960. Soil classification. A comprehensive System, 7th Approximation (and 1967Supplement). U.S. Dept. Agr., 25 pp.

Van Amson, F.A., 1966. Some aspects of clay soils in the Demerara Formation of Surinam. Bull. Agr. Expt. Sta., Paramaribo, 84: 26 pp.

Van den Eijk, J.J., 1957. Reconnaissance Soil Survey in Northern Surinam. Thesis, Wageningen.

IJzerman, R., 1931. Outline of the Geology and Petrology of Surinam (Dutch Guiana). Thesis, Utrecht, $27 \mathrm{pp}$.

Zonneveld, J.I.S., 1954. Waarnemingen langs de kust van Suriname. Tijdschr. Koninkl. Ned. Aardrijkskundig Genoot., $71: 18-31$. 